\title{
HISTÓRIA DE MULHERES NEGRAS, PROFESSORAS, EX- COTISTAS E SUAS MEMÓRIAS DE INFÂNCIA E DE ADOLESCÊNCIA NA ESCOLA
}

\author{
HISTORY OF BLACK WOMEN, TEACHERS, EX-QUOTA STUDENTS AND THEIR MEMORIES OF \\ CHILDHOOD AND ADOLESCENCE AT SCHOOL
}

\author{
https://orcid.org/0000-0002-5765-9098 Kelly da Silva ${ }^{\mathrm{A}}$ \\ (D) https://orcid.org/0000-0002-5681-0753 Anderson Ferrari ${ }^{\text {B }}$ \\ ${ }^{\text {A }}$ Universidade Federal de Juiz de Fora (UFJF), Juiz de Fora, MG, Brasil \\ ${ }^{\text {B }}$ Universidade Federal de Juiz de Fora (UFJF), Juiz de Fora, MG, Brasil \\ Recebido em: 20 abr. 2021 | Aceito em: 20 ag. 2021 \\ Correspondência: Kelly da Silva (kelserena2003@gmail.com)
}

\begin{abstract}
Resumo
De uma pesquisa mais abrangente com mulheres negras nos seus processos de formação docente, como cotistas de uma universidade pública estadual, selecionamos dois pontos para analisar: suas histórias de vida e trajetórias escolares na infância e na adolescência. Nossa pretensão é pensar que a constituição dessas mulheres negras professoras antecede a formação inicial. Nesse sentido, queremos explorar a discussão interseccional entre gênero, raça a partir da perspectiva pós-estruturalista que considera que somos sujeitos resultados de discursos. Vamos trabalhar com cinco mulheres negras professoras e ex-cotistas da primeira turma de Pedagogia, a partir da política de cotas, assumindo a entrevista narrativa como procedimento metodológico que aciona memórias e conhecimentos sobre si.
\end{abstract}

Palavras-chave: mulheres negras; professoras; memórias; infâncias; adolescências.

\begin{abstract}
From a more comprehensive survey of black women in their teacher education processes, as quota holders at a public state university, we selected two points to analyze: their life histories and school trajectories in childhood and adolescence. Our intention is to think that the constitution of these black women teachers precedes the initial formation. In this sense, we want to explore the intersectional discussion between gender, race from the post-structuralist perspective that considers that we are subject to discourse results. We will work with five black women teachers and former quota holders from the first class of Pedagogy, based on the quota policy, assuming the narrative interview as a methodological procedure that triggers memories and knowledge about themselves.
\end{abstract}

Keywords: black women; teachers; memories; childhood; adolescence. 


\section{Introdução}

A lei de cotas n. 12.711 foi sancionada em 29 de agosto de $2012^{\mathrm{i}}$. Apesar disso, as cotas já eram uma realidade na Universidade do Estado de Minas Gerais (UEMG) desde 2004. A política de cotas se tornou uma exigência da lei estadual n. 15.259, de julho de 2004, que obrigava as instituições do Estado a separar, em cada curso, 20\% das vagas para afrodescendentes; $20 \%$ para candidatas e candidatos que estudaram em escolas públicas e outros $5 \%$ para deficientes e indígenas ${ }^{\mathrm{ii}}$. A primeira turma do curso de Pedagogia, a partir da política de cotas, concluiu a formação entre 2008 e 2009. Eram ao total 12 pessoas que foram contempladas por essa conquista, sendo oito mulheres e quatro homens. Todas e todos concluíram o curso. Interessados pela trajetória escolar e história das mulheres que fizeram parte dessa primeira turma, como cotistas e, portanto, que fazem parte da história da instituição, realizamos uma pesquisa de doutorado em Educação com a seguinte questão a ser investigada: como as egressas cotistas do curso de Pedagogia da UEMG-Belo Horizonte se construíram como professoras e lidam com a temática da interseccionalidade entre gênero e raça no espaço da sala de aula?

Das oito mulheres negras ex-cotistas que se formaram, apenas cinco retornaram o contato, aceitando participar da investigação. O que trazemos aqui, portanto, é resultado desse trabalho mais abrangente, com o propósito de pensar tanto a formação inicial quanto a continuada, considerando que o fazer-se professora diz de um processo permanente que antecede a entrada na graduação, passando pela formação inicial às questões do exercício da docência e que nos convocam constantemente a colocar nossas formas de pensar e agir sob suspeita.

A trajetória escolar de nossas entrevistadas até o ensino médio demonstra que elas sofreram violência, discriminação e preconceito racial desde a educação infantil. Algumas citaram a importância das políticas de ações afirmativas para romper com essa continuidade de maus tratos na escola. Trataram também da necessidade de que as professoras e os professores estejam capacitadas e capacitados para lidar com a temática em sala de aula e em todo ambiente escolar, pois o tema perpassa toda a escola. Descrevem que não viram, na infância e adolescência, ações de suas professoras para inibir as violências que sofriam e que, ainda hoje, conseguem perceber que existem muitas barreiras para atuar com a temática.

Ao abordarmos questões que envolvem a construção de identidades de professoras, tratamos de temas que se inter-relacionam a partir de processos complexos, tais como gênero e 
raça. A construção das identidades se constitui como um processo interminável e, em se tratando da problematização no "fazer-se professoras negras", ele diz de um certo jogo entre a identificação e o afastamento do que se espera de uma professora negra. Ao tomar a questão problema de "como nos tornamos professoras", Roseli Cação Fontana (2005) se dedica a pensar esse processo ambíguo entre a identificação e o afastamento da identidade de professora no seu eterno fazer e afirmar esse jogo, que envolve surpresa ao descobrir como nos tornamos o que somos. Isso porque é esse jogo que lida com o possível, com o desconhecido, com o riso e com a tensão que buscamos provocar nas participantes desta pesquisa, ao assumir a entrevista narrativa como ferramenta que aciona as memórias.

Para adentrar esse campo tão fértil de ideias e conceitos que vão formando nossas identidades como professoras e professores, trabalhamos com as narrativas que nos chegam pelas entrevistas, pelas lembranças das nossas participantes. A entrevista é compreendida como uma narrativa de si, numa perspectiva pós-estruturalista, o que significa dizer que a entrevistanarrativa possibilita que nós, pesquisadoras e pesquisadores, na relação com o outro, sejamos capazes de ressignificar nossas formas de pensar e agir nas nossas trajetórias pessoais e de investigação (ANDRADE, 2012). Com isso, estamos assumindo o pressuposto pósestruturalista de que os sujeitos são produzidos no âmbito da linguagem, nas suas relações com os discursos, que nos nomeiam e nos governam. Somos produtos dos discursos, daquilo que falam e de que somos capazes de falar sobre nós mesmos. A escola é um desses lugares de produção dos sujeitos, espaço em que se nomeiam e governam os corpos. Nesse sentido, ao pensarmos os processos de constituição das professoras, é importante recuperarmos suas histórias e trajetórias pessoais nas escolas, argumentando que vamos nos tornando professoras e professores antes mesmo de entrarmos na graduação, já que a escola também produz modos de se narrar, de dizer de si a partir das experiências lá vividas, que nos aproximam e nos afastam de modelos de professora e professor.

Tivemos dois encontros individuais com cada uma delas realizados num "lugar de memória", na biblioteca da Faculdade de Educação da UEMG, onde tinham cursado a graduação. Para Pierre Nora (1993), os "lugares de memória" misturam história e memória de forma híbrida, já que não é possível mais ter somente memória, sendo necessário identificar uma certa origem que associe a memória ao passado. Estar num lugar em que viveram, um lugar que marca a origem é um convite a lembrar. Aceito o convite, a entrevista foi composta de questões relacionadas à trajetória de vida das professoras desde a educação infantil aos dias 
atuais. As questões estavam concentradas nas suas relações com a escola e nos temas que elas lembravam ou a respeito dos quais desejavam falar, livremente.

As cinco participantes foram identificadas por pseudônimos, com o objetivo de preservar o anonimato recomendado pelos princípios da ética em pesquisa. Os pseudônimos escolhidos por nós foram inspirados em mulheres negras que, ao longo de suas trajetórias de vida, desempenharam papéis de relevância na história de luta das mulheres negras brasileiras elou mulheres que tiveram seus destinos encerrados pela violência contra a população negra, demonstrando, na prática, nosso racismo estrutural.

Assim, Cláudia é uma homenagem a Cláudia Silva Ferreira, assassinada e arrastada por 350 metros, tendo parte do seu corpo dilacerada. Cláudia é uma professora de 35 anos de idade, formada há nove anos e, ao mesmo tempo, atua como professora na rede municipal de Belo Horizonte, lecionando em duas escolas de educação infantil. Carolina é uma forma de reconhecer a importância da escritora Carolina Maria de Jesus. Carolina é uma professora de 32 anos de idade, que atua há nove anos nos anos na educação infantil e anos iniciais da educação básica da rede municipal de Belo Horizonte e na rede particular de ensino. Lélia é uma saudação de respeito pela contribuição da ativista e intelectual Lélia Gonzáles aos estudos de gênero, atravessado por raça. Lélia é uma professora de 46 anos de idade que leciona na rede municipal e estadual de ensino de Belo Horizonte, atuando nas séries iniciais da educação infantil. Elza é uma reverência à cantora Elza Soares. Elza é uma professora de 45 cinco anos, que ensina na rede municipal de Belo Horizonte há nove anos, nas séries iniciais da educação básica, atuando também como especialista da educação básica. Marielle é um tributo à vereadora Marielle Franco, brutalmente assassinada. Marielle é uma professora de 47 anos de idade que atua há nove anos, lecionando em duas escolas da rede municipal de ensino de Belo Horizonte nos anos iniciais da educação básica. Com as narrativas dessas professoras, conhecemos algumas histórias de vida e concepções acerca de seus processos de formação, suas vivências no que diz respeito à educação para as relações étnico-raciais.

Para a organização do texto, este artigo se divide em dois tópicos em que apresentamos, primeiramente, as narrativas das professoras negras sobre suas trajetórias na infância com a família e a entrada nas escolas. Num segundo momento, as narrativas são tomadas como provocativas para pensar sobre a construção das identidades dessas professoras como crianças negras nos anos iniciais do ensino fundamental, mantendo, ainda, a relação das experiências nos encontros entre família e escola. Nosso argumento é que essas histórias e experiências constituem essas professoras, de tal forma que as ações delas com suas alunas negras não são 
possíveis sem esse olhar para o que foram, o que passaram e o que conquistaram como formação.

\section{Trajetórias escolares e pessoais de professoras ex-cotistas: infâncias e escolas}

O uso de infâncias e escolas no plural se justifica em função do nosso entendimento de que não é possível pensar em uma única concepção de infância e de escola. Ao contrário de entendê-las como algo dado, pronto e imutável, procuramos o viés da produção das diferenças para problematizá-las como tempo e espaço resultado de discursos e de histórias. As infâncias dessas professoras se encontram com as de suas alunas negras atuais, num exercício de identificação e afastamento na construção da diferença. Ao mesmo tempo em que se identificam com suas alunas negras, também se diferenciam e se afastam pela produção da diferença das histórias de vida, pelo investimento que realizam para que possam ser diferentes e passar por experiências distintas daquelas que as marcaram. Nesse sentido, seguimos as provocações de Jorge Larrosa (2000) na afirmação da infância como produção das diferenças. Para o autor, a infância "como um outro não é o objeto (ou o objetivo) do saber, mas é algo que escapa a qualquer objetivação e que se desvia de qualquer objetivo" (LARROSA, 2000, p. 185). O que o autor defende é a dificuldade de se trabalhar com infância no singular, exigindo-nos pensar em infâncias, sempre no plural. A alteridade da infância é algo muito mais radical: "nada mais, nada menos, que sua absoluta heterogeneidade em relação a nós e ao nosso mundo, sua absoluta diferença”. (LARROSA, 2000, p. 185).

O convite para ressignificar suas infâncias, para pensar suas experiências infantis nessa instituição específica - a escola - foi um convite a partir do presente, um convite que reforça o lugar da professora negra, que volta seu olhar para outras crianças negras a partir da sua história de vida e trajetória escolar. Assim como não estamos trabalhando com um sentido único e homogeneizador para pensar as infâncias, também não queremos dizer que haja um "ser menina negra" típico, mas colocamos em movimento um certo jeito de produção das diferenças das infâncias de meninas negras que leve a problematizar a prática docente e seus efeitos na constituição de outras meninas negras. Revisitar e ressignificar o passado para pensar o ser professora negra, no presente, é lidar com a união entre teoria e vida, entre teoria e prática. Michel Foucault (2006) é um dos autores que nunca separava teoria e prática. Nesse sentido, ele nos ensina que essa separação é impossível pela precariedade dos nossos discursos, entendidos como processo, como possibilidades contínuas de transformação, como convites para nos distanciar de nós mesmos para pensar diferente do que se pensa. Pensar que há sempre 
possibilidades de discursos é uma forma de afirmar que as coisas ditas são sempre históricas, estão ancoradas num tempo. As narrativas construídas não são simples falas, elas dão vida, elas formam os objetos de que falam. Narrar a si mesma é uma provocação a se desprender de si mesma para fazer diferente. Isso diz de um processo de constituição de sujeitos e formação docente.

Iniciamos as entrevistas solicitando às professoras que relatassem sobre suas memóriasexperiências familiares e na educação infantil. Todas as cinco professoras-negras ex-cotistas foram as primeiras das suas famílias a ingressar na Universidade pública, como elas fizeram questão de evidenciar para dizer que essa era uma ruptura importante nas suas trajetórias escolares marcadas por dificuldades. Nesse sentido, as cotas foram fundamentais para diminuir as barreiras de ingresso à Universidade. A partir do que lembravam e narravam, iam construindo suas histórias de vida marcadas por experiências. Essas narrativas nos mostravam que havia intercessões e diferenças entre elas e nos seus processos de subjetivação.

Podemos pensar que a memória é um artefato de identidade, um aspecto importante para criar uma ideia de grupo (no caso, o grupo das professoras), de maneira que ela condiciona as relações de poder que vão variar de cultura para cultura e dentro de uma mesma cultura (HALBWACHS, 1990). Com isso, queremos dizer que as professoras, individualmente, são capazes de formular e desenvolver seus saberes como professoras com a participação do que são capazes de lembrar, dando sentido às suas práticas e repertórios.

Ao lembrarem de suas dificuldades como crianças nas suas relações com os problemas familiares e aqueles apresentados na escola, elas são capazes de pensar suas ações como professoras e de fazer escolhas atravessadas por essas memórias. Apenas Cláudia e Carolina ingressaram no ensino superior após o ensino médio, sendo que Cláudia havia tentado o ingresso por dois anos seguidos, sem sucesso. As demais entrevistadas só ingressaram mais velhas, depois de um período de distanciamento entre a escola e a Universidade. Os motivos que vão sendo apresentados ao longo do relato de suas trajetórias evidenciam dificuldades que dizem da problemática entre raça, gênero e classe. Trata-se de narrativas que nos alertam para as várias possibilidades de atuação na educação infantil e sobre como essas mulheres lidam hoje com a temática de gênero e raça nas escolas em que atuam.

Claudia: Nasci em uma família composta por pai, mãe e uma irmã (6 anos mais nova que eu). Era muito complicado, meu pai era alcoólatra, minha mãe que segurava o casamento. Só separou quando a gente já tinha mais de 18 anos, porque ela tinha muito medo de ficar sozinha com duas filhas (...) a gente morava era periferia da Região Metropolitana, no bairro Novo Progresso em Contagem, onde eu moro até hoje. (...) apesar de ser uma família dita tradicional, com pai, mãe, filho, cachorro, a gente tinha muitas dificuldades devido ao problema do meu pai com o álcool. Então 
era bem conturbada a relação dos dois, assim como minha infância e minha adolescência. Minha mãe era empregada doméstica, meu pai era padeiro, eu fui a primeira a ter um curso superior da família toda e ainda hoje são poucos os que chegaram ao curso superior, apenas alguns primos. Minha irmã mesma não concluiu nem o Ensino Fundamental, pois foi mãe muito jovem, exatamente por causa dos problemas familiares, porque era muito ruim ficar na minha casa, ela logo começou a ter amizades fora de casa e engravidou com 15 anos. (...) O filho da minha irmã atualmente tem 14 anos e vive comigo e minha mãe, porque depois que ele nasceu minha irmã teve alguns problemas e quando ela se casou e quis levá-lo, ele não quis mais ir com ela.

Carolina: Minha família era composta por mim, minha mãe, meu pai e meu irmão. Meus pais não eram casados oficialmente, mas moravam juntos e nunca se deram muito bem, inclusive hoje meu pai já não mora mais com a gente, sempre tinham muitas brigas devido ao fato de meu pai ser alcoólatra. Minha mãe trabalhava na escola como auxiliar de limpeza e nenhum dos dois tinha muito estudo, minha mãe concluiu a $8^{a}$ série e meu pai, a $4^{a}$ série. Minha mãe sempre incentivou a mim e a meu irmão a estudar, sempre falava que se não quiséssemos ter a vida difícil que ela tinha, deveríamos estudar, muitas vezes não tínhamos nem o que comer direito e ela sempre me direcionava para leitura, como meio de "esquecer as dificuldades". Devo meu gosto pela leitura a ela. Mesmo minha mãe não tendo muito estudo, ela fazia "provinhas" para mim e se ela não soubesse a matéria, procurava alguém que pudesse me ajudar, sempre nos encaminhando para os estudos.

Ao ressignificar suas memórias, Cláudia nos relata que a infância foi marcada pela difícil relação entre os pais - um padeiro e uma doméstica - que tentavam enfrentar juntos o alcoolismo do pai, avaliado como o principal problema para o bom desenvolvimento familiar. A mãe aguardou a filha mais nova completar 18 anos para se separar, pois tinha receio do julgamento moral dos outros para uma mulher solteira criando duas filhas na periferia. Sua irmã engravidou aos 15 anos e não terminou o ensino fundamental. Segundo Cláudia, sua irmã não gostava de ficar em casa, para evitar contato com as divergências entre os pais.

Três mulheres - mãe e duas filhas - que vão se constituindo juntas, vão estabelecendo relações atravessadas pelas questões de raça, gênero e classe. Não é difícil encontrar relatos semelhantes a esse, que vão construindo e enquadrando um certo saber sobre a realidade de meninas negras da periferia: problemas familiares que resultam em trajetórias escolares difíceis. A narrativa de Cláudia, no entanto, foge a essa ideia de insucesso motivado pelas dificuldades, incitando-nos a pensar nas relações entre aquilo que lembramos (que nos marca) e contamos, entre essas narrativas e a produção de significados. Contar das dificuldades também é uma forma de falar da superação, de se entender como capaz de enfrentar e vencer os obstáculos, construindo uma imagem forte de si. Nossas narrativas são resultados das produções de significados que nos constituem, da mesma forma em que vamos produzindo significados através da linguagem. Segundo Maria Lúcia C. Wortmann (2002, p. 81), “as linguagens são centrais para o significado e para a cultura, por serem os repositórios chaves de valores e de códigos que dão sustentação aos diálogos”. A autora acrescenta ainda que é a linguagem que 
permite "a construção de entendimentos partilhados, que possibilitam aos sujeitos interpretarem o mundo de maneira mais ou menos parecida e a se tornarem membros de uma cultura". (WORTMANN, 2002, p. 81).

As lembranças de Cláudia estão recheadas de valores que sustentam seus saberes de mulher e fazem compartilhar os significados entre sua mãe e sua irmã. Ela não constrói a si sozinha, ela chama sua mãe para produzir uma imagem de mulher vitoriosa, com uma moral, que foi capaz de criar duas filhas, de aguentar a doença do marido até a filha menor completar a maioridade, fortalecendo o lugar da mulher como do "cuidado" dos outros. Para Foucault (1988), a “experiência de si” diz dessas práticas relativas ao corpo, à alma, à sexualidade, ao gênero, experimentadas numa certa temporalidade que vão conferindo identidade individual e coletiva. Se, no tempo da mãe de Cláudia, ela estava marcada por uma preocupação com o que os outros iriam pensar de uma mulher separada com duas filhas, hoje, essa ainda é uma preocupação que marca as experiências de outras mulheres com o seu corpo, gênero e sexualidade.

Carolina, seguindo o mesmo caminho narrativo de Cláudia, também nos relata uma infância marcada por dificuldades. Os pais semianalfabetos também tinham muitas dificuldades na criação dos dois filhos devido ao alcoolismo do pai e à submissão da mãe ao modelo social a que era imposta, chegando a família a não ter como se alimentar em alguns momentos. A mãe tentava burlar isso com a leitura, incentivando os filhos a estudar para que não passassem pelas dificuldades por que ela passava. A autora Conceição Evaristo (2016), em seu livro intitulado "Olhos d'água", relata que sua mãe também contava histórias para distrair as filhas da fome. Foi justamente nos momentos em que havia pouco ou nenhum alimento que as brincadeiras e as histórias aumentavam a aproximação entre mãe e filhos (EVARISTO, 2016). De acordo com a professora Carolina, o seu "gosto" para leitura e estudos veio do incentivo da mãe: "Minha mãe sempre incentivou a mim e a meu irmão a estudar, sempre falava que se não quiséssemos ter a vida difícil que ela tinha, deveríamos estudar”. A leitura e o estudo eram passados como uma forma de "esquecer as dificuldades". O reconhecimento de Carolina da ação de sua mãe na sua constituição como leitora é marcante: "Devo meu gosto pela leitura e estudos a ela". Novamente é a ideia de mulher forte que Carolina constrói, aquela que é capaz de superar as adversidades: "Mesmo minha mãe não tendo muito estudo, ela fazia "provinhas" para mim e, se ela não soubesse a matéria, procurava alguém que pudesse me ajudar, sempre nos encaminhando para os estudos". 
Pensar as questões de gênero nos relatos sobre o cuidado da mãe com as filhas e os filhos e a preocupação com os estudos nos remete ao que Joan Scott (2019) discute sobre o conceito de gênero ter sido criado para contrapor a um determinismo biológico nas relações entre os sexos, dando-lhes um caráter fundamentalmente social. Nessa negação do gênero como essência e no investimento como construção social e histórica, o termo passa a ter uma perspectiva relacional que vem do incômodo de algumas e alguns de que os estudos feministas tinham pouco foco nas questões sobre as mulheres. Assim, a noção de gênero daria conta de que as mulheres e os homens eram definidas e definidos em termos binários e não poderiam ser entendidas e entendidos separadamente. Pensando o gênero enquanto "categoria de análise", Joan Scott (2019) sugere uma mudança dos paradigmas tradicionais do conhecimento, possibilitando a investigação das relações de gênero a partir de uma produção histórica do conceito e dos sujeitos, algo que inclua outros discursos, numa perspectiva que considere o sentido e a natureza das opressões e dos jogos de poder aí presentes.

Como nos mostram Joan Scott (2019), Nancy Fraser (2019) e Sueli Carneiro (2019), o termo nasce para possibilitar a análise das diferenças entre mulheres e homens numa perspectiva relacional. Mas parece inegável que o conceito também ganha força entre mulheres feministas, ao perceberem que estariam permitindo o surgimento de uma nova história. Conforme destaca Scott (2019, p. 51), “a maneira como esta nova história iria simultaneamente incluir e apresentar a experiência das mulheres dependeria da maneira como o gênero poderia ser desenvolvido como uma categoria de análise". No argumento de que as palavras têm história, Joan Scott defende que o surgimento da palavra gênero "indicava uma rejeição do determinismo biológico implícito no uso de termos como sexo ou diferença sexual. $\mathrm{O}$ termo gênero enfatizava igualmente o aspecto relacional das definições normativas da feminilidade". (SCOTT, 2019, p. 72).

Enfim, o surgimento do conceito de gênero foi importante para problematizar dois aspectos. O primeiro é aquele que considera que as diferenças entre mulheres e homens são construídas no social. Portanto, dizem de uma construção e não de essência, algo que, ao ser questionado, coloca a importância de levar em consideração nossa cultura para pensar os procedimentos, os discursos, as estratégias e as performances de construção dos sujeitos mulheres. O segundo aspecto é aquele que escolhe as relações de gênero como termo a ser utilizado quando falamos de mulheres e homens, ressaltando o caráter relacional que constitui esses sujeitos e, mesmo que se estabeleçam certo binarismo e fronteira entre eles, cada vez mais está sendo problematizado e colocado sob suspeita. 
Assim, o surgimento das relações de gênero está diretamente ligado à história do movimento feminista, que vem questionando a condição das mulheres nas suas relações com a sociedade ocidental desde o século XIX. A maioria dos direitos de que as mulheres desfrutam hoje foram alcançados por meio de um longo processo de lutas de grupos específicos de mulheres, que se organizaram para apontar as desigualdades históricas existentes entre mulheres e homens e para exigir tratamento igualitário entre elas e eles no exercício de direitos civis e políticos. Analisando a relação das mães com nossas professoras entrevistadas, percebemos como ficam, para as mulheres, determinados papéis sociais, tal como o do cuidado.

Tanto Carolina quanto Cláudia citaram as dificuldades de ser criança negra, mesmo tendo pai e mãe. Em ambas, a infância foi marcada pela doença do pai, mas, sobretudo, pela presença e cuidado da mãe. O conceito de cuidado está historicamente ligado ao feminino. Nesse sentido, as profissões que lidam diretamente com o cuidado vão também, a partir da ascensão feminina ao mercado de trabalho, tornando-se profissões ocupadas, em sua maioria, por mulheres, tais como a enfermagem e a educação infantil. De acordo com Louro (1997), as diferenças entre mulheres e homens estão relacionadas às características biológicas. Para Meyer (2002), o cuidado representa "múltiplas e conflitantes formas", ao longo dos séculos XIX e primeira metade do século XX, em diferentes nações, países e culturas, especialmente nos momentos de crise, em que as mulheres eram entendidas como "responsáveis pela saúde física, emocional e moral do corpo social, como esteio do lar e da família, como agentes de purificação e regeneração racial, como educadoras e símbolos da nação e da pátria e, em contrapartida, como o oposto de tudo isso" (MEYER, 2002, p. 124). O cuidado das mães com a importância da educação levou essas duas professoras não só a gostarem da escola, como se constituíram nesse processo, prolongando a ideia do cuidado com os outros.

A profissão docente permitiu às mulheres o acesso a um dos espaços públicos anteriormente frequentado pelos homens. No entanto, essa profissão vai ser representada como similar ao trabalho no lar, pela sua função primordial que é o cuidado com as crianças. Essa concepção é utilizada para naturalizar/reforçar o magistério, especialmente das séries iniciais, como uma profissão feminina. Dessa forma, as mulheres se constituem maioria no espaço do magistério, ressaltando que, como destaca Teixeira (2006), essa presença se dá de forma diferenciada entre mulheres brancas e negras, estando as mulheres negras nas séries iniciais, em sua maioria. Conforme Louro (1997, p. 88) “elas organizam e ocupam o espaço, elas são as professoras; a atividade escolar é marcada pelo cuidado, pela vigilância e pela educação, tarefas tradicionalmente femininas". As práticas se constituem como naturais. Nesse processo de 
feminização do magistério, ocorre também a transferência dos predicados do lar - cuidado, carinho, amor, dedicação, vocação - para esse campo. Essa atividade é considerada uma continuidade da educação primária do lar e esses atributos vão constituindo o feminino.

Demonstrar as diferentes formas como as mulheres foram submetidas à dominação masculina ainda é uma luta constante. As violências que as mães de nossas entrevistadas sofreram não foram relatadas com detalhes, mas se expressaram nas lágrimas em meio às lembranças durante a entrevista. A dor da lembrança perpassou a entrevista de quase todas as professoras, sendo intercalada por momentos de alegria e orgulho de terem conseguido chegar onde estão. A ideia do sofrimento e da vitória serve para valorizar o lugar que ocupam hoje.

Elza foi a mais empolgada com o encontro. Desde o primeiro contato, ela insistiu em participar e justificou dizendo que as cotas são ainda muito necessárias e que precisamos falar sobre elas e sobre as/os cotistas nas instituições. Elza vem de uma família com nove irmãos, pais analfabetos, e vivenciou as mazelas da pobreza e o descaso com a educação da população do campo, nas salas multisseriadas, relatando que a condição da família beirava a miserabilidade:

\begin{abstract}
Elza: Sou de uma família do norte de Minas, região de Montes Claros, no total de 10 irmãos, nós éramos mais que pobres, éramos miseráveis. Eu iniciei minha trajetória escolar ainda lá na zona rural, meu pai teve que brigar na escola para que eu pudesse estudar lá, pois eu ainda ia fazer 7 anos. Naquela época não era aceito, me aceitaram na condição de que eu não atrapalhasse as aulas, que ficasse bem quieta, fiquei um ano apenas aprendendo a escrever meu nome. Fui aprendendo de tanto ver e estar mergulhada nesse mundo, eu me lembro que tinha uns livros do MOBRAL que eram do meu avô, que me encantavam. A minha família era composta por analfabetos $e$ semianalfabetos. Minha mãe lia um pouco e meu pai era analfabeto, apenas desenhava o nome, mas não reconhecia as letras. Eram muitas dificuldades financeiras, minha mãe era muito religiosa, considerava pecado tomar anticoncepcional e por isso tinha muitos filhos.
\end{abstract}

Trata-se de uma narrativa atravessada por raça e classe: "nós éramos mais que pobres, éramos miseráveis". A desigualdade de classe, de acordo com Ribeiro (2006), não pode ficar de fora em um debate sobre interseccionalidade de classe, raça e gênero. Essa desigualdade se caracteriza pela dificuldade de acesso a recursos e meios de produção, constituindo uma distância social entre os grupos com mais ou menos recursos. Essa é outra desvantagem que a maioria das populações negras em nosso país encontra e que impede o indivíduo de alcançar posições hierarquicamente superiores pela dificuldade de acesso à educação, saúde e, consequentemente, a melhores postos de trabalho. Além disso, essa desigualdade parece ser mais facilmente reconhecida, ao contrário das desigualdades de gênero e raça que ainda são sutis, permanecendo por muito tempo silenciadas e, por isso, difíceis de documentar (RIBEIRO, 
2006). Elza, relatando em sua trajetória diversas violências que se acumulam frente às intersecções de sua identidade, destaca que ficara por um ano na escola apenas aprendendo a escrever seu nome, em uma sala multisseriada em uma comunidade rural.

Marielle descreve sua infância como importante por ter sentido necessidade de se posicionar desde nova, para ser respeitada pelos colegas. Filha do meio entre mais dois irmãos sempre teve incentivo dos pais para o estudo. Já Lélia vem de uma família de seis irmãos, não teve muitas dificuldades financeiras na infância e todos os irmãos terminaram o ensino médio.

Marielle: Minha família era formada por mim, meu pai, minha mãe e meus 2 irmãos. Eu sou a irmã do meio. Eu sofri muito na infância com preconceito, então eu tinha que me posicionar desde nova, para ser respeitada, assim me formei.

Lélia: Venho de uma família grande, pai, mãe e 6 irmãos, minha mãe era dona de casa e meu pai pedreiro, posso dizer que nossa vida financeira não foi difícil, eles fizeram de tudo para que nós estudássemos, todos nós 6 concluímos o ensino médio.

As trajetórias das mulheres negras, nas suas infâncias, perpassam diferentes cruzamentos no que se refere às suas construções sociais. As violências apresentadas pelo sexismo e racismo se misturam, aumentando a complexidade de suas discriminações. Podemos perceber essas implicações nas histórias de algumas mães de nossas entrevistas que se permitiram ser violadas em seus desejos de liberdade e melhores condições de vida, até que seus filhos atingissem certa idade, por medo do que falariam os "vizinhos" ou para que as crianças não fossem mal vistas pela sociedade, violações que se dão pela violência do sexismo, do racismo e da classe social, questões bem diferentes das lutas de mulheres brancas. De acordo com Carla Akotirene (2019, p. 534), é por meio dessa relação entre "raça, gênero, classe e território, que os fracassos das políticas públicas são revertidos em fracassos individuais".

É nesse sentido que Kimberle Crenshaw (2002) ressaltou que devemos pensar as questões referentes às discriminações de gênero de mulheres negras numa perspectiva interseccional. A briga contra a violação de direitos das mulheres negras deve, dessa forma, levar em consideração a complexidade das vulnerabilidades a que as mulheres estão expostas, pois as desigualdades de gênero, raça e classe se entrecruzam e se intensificam (CRENSHAW, 2002). Depois de sabermos um pouco sobre a infância das nossas professoras ex-cotistas, questionamos suas memórias a respeito de suas primeiras relações com a escola.

\section{Socialização e construção de identidades: anos iniciais do ensino fundamental}

Da infância à adolescência, da educação infantil ao ensino fundamental, as questões da violência permanecem, com novas roupagens, novos termos, mas com a mesma lógica de construção dos saberes em torno das mulheres negras. Marielle e Cláudia tocam nessas 
continuidades, ao relatarem como eram recebidas nas escolas pelos colegas e como se portaram em suas vidas a partir dessas experiências:

Marielle: Sempre sofri o que chamamos de "bullying" hoje, por causa da minha cor, mas eu sempre me defendi dentro da escola, isso me tornou forte, eu percebi que eu precisava ser atrevida para sobreviver e acabou dando certo. Muitas vezes, nós, crianças negras, quando reagimos às violências, éramos chamados de brigões, mentirosos, como se fôssemos nós que permitíssemos essas violências.

Cláudia: Ingressei na escola na década de 90, mais especificamente em 1991, e sofri muito com "bullying", por ser uma criança negra, que não tinha aquele "cabelo de princesa". Sofri muita discriminação, racismo, recebia apelidos pejorativos, estudei nesta escola até o $9^{\circ}$ ano do ensino fundamental.

A violência pela qual Marielle e Cláudia passaram na escola é classificada como bullying, mas na época em que elas sofriam essas violências, não era esse o nome dado a esse tipo de violência, tampouco era considerado racismo. Racismo e bullying são dois termos datados e incorporados ao conhecimento e vocabulário atuais. Acessar as memórias é sempre um processo a partir do presente, o que faz com que Marielle classifique hoje o que vivia na adolescência: "Sempre sofri o que chamamos de 'bullying' hoje, por causa da minha cor". O advérbio de tempo "sempre", que ela utiliza, ultrapassa a adolescência e nos fornece pistas de que esse processo ocorria antes desse período escolar e continua depois dele. Ela não somente chama de bullying, mas também consegue definir que essa violência se concentrava nas questões raciais, era motivada pela cor da sua pele. Assim, o bullying parece ser um termo geral para falar de uma violência específica, servindo para esconder seus reais aspectos, que diz de um processo histórico que marca nossa sociedade como racista. A leitura que faz dessa violência também fornece um lugar para ela na atualidade: “isso me tornou forte, eu percebi que eu precisava ser atrevida para sobreviver e acabou dando certo". De alguma forma, ela atribui a essas violências uma marca na sua personalidade, uma forma de enfrentar e resistir a elas. Para falar de si, Marielle vai e volta na temporalidade, utilizando passado e presente para construir um conhecimento de si marcado pelas experiências. Ao mesmo tempo em que fala do hoje, este é marcado pelo que ocorreu no passado. Se, hoje, ela se classifica como "forte", "atrevida", "sobrevivente" e, por isso, acaba concluindo que "deu certo" porque o resultado foi positivo, ela também consegue analisar que nem sempre foi assim. Voltando ao passado, ela também revive outra classificação do passado. Se, hoje, ela é "forte e atrevida", na infância, era classificada de "brigona e mentirosa". "Muitas vezes, nós, crianças negras, quando reagimos 
às violências, éramos chamados de brigões, mentirosos, como se fôssemos nós que permitíssemos essas violências".

Em uma pesquisa sobre bullying nas escolas, Anderson Ferrari (2010) questiona às/aos estudantes o que elas e eles compreendem por humilhar. Alguns dados chamam a atenção do pesquisador, tais como "o fato de a humilhação ter a necessidade da presença do "outro" (FERRARI, 2010, p. 22). O autor continua sua análise esclarecendo qual a função desse outro: “um 'outro' que é o diferente e alvo da humilhação, entendida como agressão verbal ou física, e um 'outro' como um terceiro que serve como aquele que dá condição à ação, visto que é o espectador" (FERRARI, 2010, p. 22). Com isso, podemos entender que é o espectador quem parece decidir quem comete e quem sofre a violência, sendo esse imprescindível nesse processo. É ele quem dá o mérito ao ganhador e ao humilhado no evento. As violências vão sendo inseridas no cotidiano e aos poucos vão se naturalizando. O autor destaca, ainda, que as questões raciais atingem tanto meninas quanto meninos no que se refere ao preconceito e discriminação racial, sendo "possível perceber que a raça ainda é entendida como forma de desigualdade e de inferioridade, de forma que o outro, o agredido, também compartilha do sentido usado para estabelecer a agressão". (FERRARI, 2010, p. 26-27). Na referida pesquisa, as alunas e os alunos diziam da materialização das violências racistas na escola: "humilhar por causa da cor", "fazer uma pessoa se sentir mal, alguém fala na frente de todos que a pessoa é negro, puxa seu cabelo", "xingar de todos os nomes, macaco, crioulo, etc", "chamavam minha colega de macaca". (FERRARI, 2010, p. 26-27).

Cláudia também cita o bullying, mas ressalta que sua professora, nos primeiros anos da educação básica, mesmo sem formação, tentava conversar com as crianças para que respeitassem as outras. Podemos perceber que as entrevistadas classificam a discriminação racial como bullying. No entanto, ao explicarem os jogos de poder e saber que organizam as agressões, elas deixam mais evidente que sofriam racismo, preconceito, assim como algumas crianças sofrem homofobia, transfobia. Assim, é preciso conhecer o tipo de violência que ocorre para que possamos lidar com ela. De acordo com Carlos Skliar (2002), vivemos em uma sociedade dividida por uma lógica binária, seja entre nós/eles, branco/preto, normal/anormal, sendo que o diferente é considerado o ruim, o erro, o que não sou. $\mathrm{O}$ silenciamento do outro ou a negação servem de estratégia para que se mantenha o ideal imposto por determinado grupo. O objetivo é homogeneizar e condenar as diferenças, incluindo-se aí tudo o que não se assemelha a mim, ou seja, o outro não deveria sequer existir. De acordo com Skliar (2002, p. 11), a "pedagogia do outro como hóspede de nosso presente é a pedagogia cujo corpo se 
"reforma" e/ou se "auto-reforma". Caracterizando mais detalhadamente essa pedagogia da "mesmice", Skliar (2002, p. 11) afirma que ela "tenta alcançar o outro, capturar o outro, domesticar o outro, dar-lhe voz para que diga sempre o mesmo, exigir-lhe sua inclusão, negar a própria produção de sua exclusão e de sua expulsão".

As análises de Skliar (2002) são uma forma de implicar a escola e a formação docente na superação dessa pedagogia de apagamento do diferente. Isso parece importante, já que a escola é sempre muito complexa, ela nunca é uma coisa somente, de maneira que não podemos dizer que no seu interior existem exclusivamente práticas discriminatórias e violentas. As professoras, ao narrarem suas trajetórias, também reconhecem momentos de enfrentamento dessas violências, trazem exemplos de professoras em que se espelham no combate ao preconceito. Um exemplo disso é a lembrança de Claudia que recorda do carinho de uma professora com todas e todos de forma igualitária. Na mesma narrativa, também menciona que sempre era preterida nas apresentações escolares atuando nas apresentações teatrais como poste, nuvem, árvore, enfim, nenhum papel relevante, como também nunca foi escolhida para ser noiva na quadrilha. Sua narrativa oscila entre boas e más lembranças.

Claudia: Um ponto positivo era a professora Márcia, que era muito carinhosa e simpática com todos os alunos, lembro direitinho, mesmo não tendo a orientação que temos hoje, ela tentava evitar os episódios de "bullying", tentava conversar com os alunos. De negativo era o "bullying", racismo, os apelidos, "gorda", "baleia", "galinha de macumba". Na época eu não percebia, mas havia, sim, preconceito, como não ser escolhida para ficar na frente da sala nas apresentações, nunca ser a noiva da quadrilha, só receber papéis pouco significativos nas apresentações, como poste, nuvem, sempre lá no fundo. Com o tempo comecei a me sentar mais para trás na sala de aula, pois sempre tinha um grupinho que se destacava mais.

Dagmar Ester Meyer, em seu artigo "Da impossibilidade de se ver como anjo" (2002), trata da importância de se debaterem os conceitos de gênero, raça, diferenças e diversidade no espaço escolar e na formação docente. Faz esse debate apresentando um relato de uma professora negra que conta a história de uma menina também negra de três anos de idade da pré-escola que se se negava a frequentar a instituição de ensino por ter percebido que ali "não poderia ser anjo”. Meyer (2002) utiliza-se desse relato para problematizar acerca das representações que estão impressas na cultura escolar e que passam despercebidas pela maior parte dos profissionais da educação. Não existir anjos negros é apenas um de muitos outros exemplos do que a escola reproduz, como as fadas, princesas e príncipes de histórias infantis sempre brancas e brancos. O branco é quase sempre representado como o belo, o puro, o do bem, enquanto o negro é impuro, é do mal, é feio, sem contar a articulação mulher e raça/cor 
negra. Todos esses saberes/poderes transmitidos às crianças desde muito cedo constituem o currículo, mesmo que não o currículo formal, mas são também aprendizagens, que, reforçadas diariamente, mesmo que indiretamente, produzem pensamentos e atitudes de preconceito e exclusão. A despeito de a professora estar atenta para impedir os maus tratos diretos dos colegas à Cláudia, estruturalmente, não agia para colocá-la como protagonista.

Petronilha Beatriz da Silva (2007) destaca a importância da formação docente, tanto a inicial quanto aquela realizada em serviço, para a educação de nossas crianças, orientando a necessidade de analisar a maneira como as crianças aprendem. $\mathrm{O}$ racismo atua tentando fazer parecer que a vítima é culpada pela desigualdade que sofre, como parece ser o caso de Cláudia em sala. Cláudia e Marielle dizem dessa produção do racismo como efeitos de discursos, ao mesmo tempo em que ele - o racismo - também produz discursos e sujeitos, que "procuram normalizar as diferenças entre os sujeitos, atribuindo-lhes a responsabilidade pelas desigualdades sofridas”. (OLIVEIRA; MENEGHEL; BERNARDES, 2009, p. 269). Um desses resultados discursivos do racismo é que "são veiculadas normas e prescrições para a população negra, que funcionam como máquinas de agenciamento de identidades e subjetividades homogêneas, passivas e assujeitadas (OLIVEIRA; MENEGHEL; BERNARDES, 2009, p. 269).

Além dessa construção de identidades, constrói-se também um imaginário coletivo com representações que se propagam na sociedade e a escola não fica fora desse processo. De acordo com Cavallero (2010), uma ideia inferior de negros, bem como a valorização de brancos, pode ser interiorizada, no decorrer da formação dos sujeitos, por interferência dos processos socializadores, ou seja, se não nos atentarmos para as violências que se reproduzem no que se refere às questões raciais, estaremos permitindo que o preconceito se propague. Dessa forma, “cada indivíduo socializado em nossa cultura poderá internalizar representações preconceituosas a respeito desse grupo sem se dar conta disso, ou até mesmo se dando conta por acreditar ser o mais correto" (CAVALLERO, 2010, p. 289). A escola é implicada diretamente nesse processo, de maneira que a "despreocupação com a questão da convivência multiétnica, quer na família, quer na escola, pode colaborar para a formação de indivíduos preconceituosos e discriminadores" e ainda "levar inúmeras crianças e adolescentes a cristalizarem aprendizagem baseadas, muitas vezes, no comportamento acrítico dos adultos a sua volta" (CAVALLERO, 2010, p. 295). 
As professoras estão nos dizendo de saberes preconceituosos internalizados em crianças. Quando Elza destaca que a relação com os colegas era ruim, que existiam xingamentos e apelidos que não eram encerrados pelos professores, ela está nos dizendo que, desde criança, ela percebia essas mazelas, que essas experiências a constituíram como mulher negra e como professora negra. A questão é pensar: como essas lembranças refletem nessas professoras hoje? Lélia faz um relato mais forte no que se refere aos preconceitos. Os xingamentos foram lembrados por ela por expressões e características da população negra, tais como nariz e boca. Relata ainda que a própria mãe, tentando atender ao que a cultura branca impõe como ideal, buscava exercícios com o nariz para afiná-lo e o pai fazia questão de pagar salão de beleza para que elas mantivessem os cabelos alisados, como vamos ver em seu relato:

Elza: Era muito ruim, muitos apelidos, xingamentos, humilhações. O meu desempenho era considerado bom, sempre sobressaímos aos demais alunos, eu e meu irmão que éramos menores aprendemos a ler primeiro que os alunos mais velhos da turma, então nosso rendimento era considerado bom.

Lélia: Em relação aos colegas, tinha situações de perseguições, apelidos, devido aos meus aspectos físicos, boca, nariz. Minha família era muito influenciada pela questão do embranquecimento, acho que era pela necessidade de serem aceitos pela sociedade, minha mãe ensinava-nos a fazer exercícios com o nariz para que ela afinasse e mesmo com dificuldades financeiras, passando aperto, meu pai pagava para nos manter com cabelos lisos, levava no salão para relaxar os fios, abaixar volume.

Para bell hooks (2019), mesmo com as muitas modificações na política racial, as mulheres negras continuam obstinadas com os seus cabelos, sendo o alisamento ainda considerado um tema importante. De acordo com Nilma Lino Gomes (2003), as experiências do negro em relação ao cabelo começam muito cedo. Para as crianças, o momento marcante do cabelo é o de início da vida escolar, "se antes a aparência da criança negra, com sua cabeleira crespa, solta e despenteada, era algo comum entre a vizinhança e coleguinhas negros, com a entrada para a escola essa situação muda". (GOMES, 2003, p.45). A escola imprime inclusive padrões estéticos, cobrando um padrão para se apresentar. A cobrança para cuidar da aparência é constante, e as justificativas para tal nem sempre apresentam um conteúdo racial explícito. Geralmente, são encobertos por necessidade de manutenção de uma ordem, demonstrando preconceitos higienistas. "Existe, no interior do espaço escolar, uma determinada representação do que é ser negro, presente nos livros didáticos, nos discursos, nas relações pedagógicas, nos cartazes afixados nos murais da escola, nas relações professor/a e aluno/a e dos alunos/as entre si” (GOMES, 2003, p. 45). Os apelidos e os xingamentos aos negros demonstram uma inferiorização desses sujeitos. Essas violências podem marcar toda a trajetória dessas crianças, 
com consequências na vida adulta. Nilma Gomes denuncia, que ainda hoje, embora os currículos e alguns docentes "se empenhem no trabalho com a questão racial no ambiente escolar, o cabelo e os demais sinais diacríticos ainda são usados como critério para discriminar negros, brancos e mestiços" para concluir que a "questão da expressão estética negra ainda não é considerada um tema a ser discutido pela pedagogia brasileira" (GOMES, 2003, p.45).

Ligado às estratégias de dominação e poder, o racismo encontra, na sociedade brasileira, caminho aberto para se desvelar e naturalizar, até que o movimento negro decide tomar a frente dos debates e pesquisas desenvolvidas sobre a temática, vivenciando, nos anos 2000, num tenso debate sobre a lei de cotas. Além de julgarem não coerentes as ações afirmativas como correção das desigualdades raciais, difundiu-se também, por meio da mídia e redes sociais, a ideia de que a qualidade das universidades iria diminuir por receber estudantes desqualificados, sem capacidade de compreender o conhecimento científico e intelectual. "De tudo isso resultou o julgamento do STF, no dia 26 de abril de 2012, o qual por unanimidade validou a adoção de políticas de reserva de vagas para garantir o acesso de negros e índios a instituições de Ensino Superior em todo o país" (GOMES, 2019, p. 1550) como uma política entendida desde o início como necessária “para corrigir o histórico de discriminação racial no Brasil”. (GOMES, 2019, p. 1550).

Para bell hooks (2019), há uma tarefa essencial para os pensadores negros críticos que é "a luta para romper com os modelos hegemônicos de ver, pensar e ser que bloqueiam nossa capacidade de nos vermos em outra perspectiva, nos imaginarmos, nos descrevermos e nos inventarmos de modos que sejam libertadores" (bell hooks, 2019, p. 323). Nesse sentido, romper com narrativa da branquitude e tecer outros discursos são essenciais para que sejam problematizadas realidades como as construídas aqui pela professoras negras ex-cotistas e para que, academicamente e na formação docente, sejam inseridos os debates que rompam com a ideia clássica de meritocracia. contribuindo para diminuir as desigualdades sociais.

\section{Considerações finais}

Ao pensarmos a trajetória de mulheres negras, é importante destacar, como podemos ver no relato de nossas entrevistadas, a interseccionalidade que perpassa o tema. Não há só a condição de mulheres, não há só a condição de negras e não há só a condição de classe. São trajetórias perpassadas por construções identitárias que "elucida(m) as articulações das estruturas modernas coloniais que tornam a identidade vulnerável, investigando contextos de 
colisões e fluxos entre estruturas, frequência e tipos de discriminações interseccionais". (AKOTIRENE, 2019, p. 526)

Todas as nossas entrevistadas tiveram sua formação na escola pública em maior parte de suas trajetórias escolares, exceto Lélia que estudou, do quinto ao nono ano, em escola particular porque o pai conseguiu bolsa para ela e dois primos. Pensar a importância da escola e, especialmente da escola pública, que, mesmo com as dificuldades que conhecemos, como de estrutura física, falta de materiais, escassa capacitação docente e necessidade de melhor remuneração aos professores, ainda assim, consegue possibilitar que muitos jovens de classe popular alcancem acesso ao ensino superior, modificando a realidade de muitas famílias. Todas as nossas professoras foram as primeiras de suas famílias a frequentar o ensino superior. Levar à formação docente o debate sobre as questões de gênero e raça tende a ampliar a possibilidade de mudanças no cenário brasileiro, no que se refere às discriminações de gênero e raça, conquistas essas que passaram pela luta do movimento negro pelo reconhecimento da diversidade étnico-racial na educação brasileira, cobrando mudanças na prática e no currículo escolares" e trazendo "para o debate público diferentes interpretações sobre a diversidade e politiza a existência múltipla, variada e dinâmica da população brasileira”. (GOMES, 2019, p. 2456).

Ainda na perspectiva do que trata Gomes (2010), repensar a trajetória da infância ao ensino médio dessas professoras nos leva ao questionamento das práticas que ainda persistem nas escolas, mesmo após implementação da Lei n. 10.639/03. A partir de suas falas, temos vários elementos que demonstram a importância de uma educação plural que valorize saberes de diferentes culturas e povos. A trajetória escolar de nossas entrevistadas até o ensino médio demonstra que elas sofreram violência, discriminação e preconceito racial desde a educação infantil. Algumas citaram a importância das políticas de ações afirmativas, como destaca Lélia: "Sou cotista. Pra mim o sistema de cotas foi um avanço, embora eu ache que atualmente ele esteja ameaçado. Eu sou uma das pessoas que defende o sistema, muitos veem como inferiorizar os cotistas, eu vejo como uma indenização mínima do que a gente sofreu no passado, eu tenho colegas que não concordam, eu deixo claro que eles não sabem o que passamos por causa da cor da nossa pele”. Trataram também da necessidade de que os professores estejam capacitados para lidar com a temática em sala de aula e em todo ambiente escolar, pois o tema perpassa toda a escola, como cita Marielle: "Eu acho importante debater esse tema gênero e raça devido à conjuntura política atual. O que mais me entristece é que esses preconceitos vêm às vezes de boca de professor e se vou debater eles alegam que eu 
defendo questões partidárias”. Descrevem que não viram, na infância e adolescência, ações de suas professoras para inibir as violências que sofriam e que, ainda hoje, existem muitas barreiras para elas atuarem com a temática. $\mathrm{O}$ fato de não haver práticas docentes de combate à discriminação e ao preconceito na infância parece colocá-las num lugar de mudar esse quadro para que outras meninas negras não passem por violências como as que elas passaram.

\section{Referências}

AKOTIRENE, Carla. Interseccionalidade. São Paulo: Sueli Carneiro; Pólen, 2019.

ANDRADE, Sandra dos Santos. A entrevista narrativa ressignificada nas pesquisas educacionais pós-estruturalistas. In: MEYER, Dagmar E.; PARAÍSO, Marlucy Alves. Metodologias de pesquisa pós-críticas em educação. Belo Horizonte: Mazza Edições, 2012. p. 173-194.

CARNEIRO, Sueli. Escritos de uma vida. São Paulo: Pólen Livros, 2019.

CAVALLEIRO, Eliane dos Santos. Do silêncio do lar ao silêncio escolar: racismo, preconceito e discriminação na educação infantil. São Paulo: Contexto, 2010.

CRENSHAW, Kimberlé. Documento para o encontro de especialistas em aspectos da discriminação racial relativos ao gênero. Revista Estudos Feministas, Florianópolis, v. 10, n. 1, p. 171-188, jan. 2002.

EVARISTO, Conceição. Olhos d'água. Rio de Janeiro: Pallas: Fundação Biblioteca Nacional, 2016.

FERRARI, Anderson. Bullying - O desafio do combate à discriminação na escola. Instrumento - Revista Estudos e Pesquisas Educacionais, Juiz de Fora, n.7, 2010.

FONTANA, Roseli A. Cação. Mediação pedagógica na sala se aula. Campinas/SP: Autores Associados, 2005.

FOUCAULT, Michel. História da sexualidade I: a vontade de saber. Rio de Janeiro: Graal, 1988.

FOUCAULT, Michel. Ética, sexualidade, política. Rio de Janeiro: Forense Universitária, 2006.

FRASER, Nancy. Feminismo, capitalismo e a astúcia da história. In: HOLLANDA, Heloísa Buarque de. (org.). Pensamento feminista: conceitos fundamentais. Rio de Janeiro: Bazar do Tempo, 2019.

GOMES, Nilma Lino. A mulher negra que vi de perto - o processo de construção da identidade racial de professoras negras. 2. ed. Belo Horizonte: Mazza Edições, 2003. 128p. 
GOMES, Nilma Lino. O Movimento Negro educador: saberes construídos nas lutas por emancipação. Petrópolis, RJ: Vozes, 2019. Edição do Kindle.

HALBAWACHS, Maurice. A memória coletiva. São Paulo: Vértice, 1990.

hooks, bell. Olhares negros, raça e representação. São Paulo: Editora Elefante, 2019. 356p.

LARROSA, Jorge. Pedagogia Profana: danças, piruetas e mascaradas. Belo Horizonte: Autêntica, 2000.

LOURO, Guacira Lopes. Gênero, sexualidade e educação: uma perspectiva pósestruturalista. Petrópolis, RJ: Vozes. 1997.

MEYER, Dagmar Estermann. "Das (im)possibilidades de se ver como anjo". In: GOMES, Nilma Lino; SILVA, Petronilha B. Gonçalves. Experiências étnico-culturais para a formação de professores. Belo Horizonte: Autêntica, 2002.

NORA, Pierre. Entre memória e história: a problemática dos lugares. Projeto História. São Paulo: PUC-SP, ${ }^{\circ}$ 10, 1993.

OLIVEIRA, Maria Luisa Pereira de; MENEGHEL, Stela Nazareth; BERNARDES, Jefferson de Souza. Modos de subjetivação de mulheres negras: efeitos da discriminação racial.

Psicologia \& Sociedade, Florianópolis, v. 21, n. 2, p. 266-274, 2009.

RIBEIRO, Matilde. O feminismo em novas rotas e visões. Estudos Feministas, vol. 14, $\mathrm{n}^{\circ}$ 3, p. 801-811, 2006.

SCOTT, Joan. Gênero: uma categoria útil para análise histórica. In: HOLLANDA, Heloísa Buarque de. (org.). Pensamento feminista: conceitos fundamentais. Rio de Janeiro: Bazar do Tempo, 2019.

SILVA, Petronilha Beatriz Gonçalves. Aprender, ensinar e relações étnico-raciais no Brasil. Educação, Porto Alegre/RS, ano XXX, vol. 63, n 3, p. 489-506, set./dez. 2007.

SKLIAR, C. É o outro que retorna ou é um eu que hospeda?: notas sobre a pergunta obstinada pelas diferenças em educação (Expositor da sessão especial A questão da diferença na Educação). In: REUNIÃO ANUAL DA ANPED, 25., 2002, Caxambu. Anais... Caxambu: ANPED, 2002.

TEIXEIRA, Moema de Poli. A Presença negra no magistério: Aspectos quantitativos. In: OLIVEIRA, Iolanda de (Org). Cor e Magistério. Rio de Janeiro: Quartet; Niterói: EdUUF, 2006.

WORTMANN, Maria Lúcia Castagna. Análises culturais - um modo de lidar com histórias que interessam à educação. In: COSTA, Marisa Vorraber (org.). Caminhos investigativos II: outros modos de pensar e fazer pesquisa em educação. Rio de Janeiro: DP\&A, 2002. 
'A referida lei, sancionada no governo Dilma Rousseff, dispõe sobre o ingresso nas universidades federais e nas instituições federais de ensino técnico de nível médio, estabelecendo cotas para pessoas autodeclaradas pretas, pardas e indígenas e com deficiência.

iiNINAS GERAIS. Lei n. 15259, de 27 de julho de 2004. Institui sistema de reserva de vagas na Universidade do Estado de Minas Gerais - UEMG - e na Universidade Estadual de Montes Claros - UNIMONTES - para os grupos de candidatos que menciona. Disponível em:

https://www.almg.gov.br/consulte/legislacao/completa/completa.html?tipo=LEI\&num=15259\&comp=\&ano=20 04\&aba=js textoOriginal. Acesso em: 15 mar. 2015 